\title{
Considerations on the Improvement of Ethical Decision Making in the Accounting Profession
}

\author{
Lecturer Alina Beattrice VLADU, PhD, Lecturer Dan Dacian CUZDRIOREAN, PhD
}

"Babeș-Bolyai" University of Cluj-Napoca, Romania

\begin{abstract}
Ethical-decision making is an overly complex process. Despite the enormous number of studies assessing it in various fields of research, much is still unknown. This paper provides an overview regarding the paths that can be used to enhance ethical decision-making process in a period when ethical challenges are set to intensity (according to the Ethics board's COVID-19 Working Group and national ethical standard-setters from various countries working under the International Ethics Standards Board for Accountants). In this respect, we consider that although the International Code of Ethics for Professional Accountants is a good path for improvement, this is not enough when guiding professional accountants. Moreover, a constant effort for combining standard-setters' provisions with prominent ethical decisionmaking models tested in the literature and innovative ethics pedagogies will result in improving ethical decision-making quality in the long run. Future research avenues are also approached.
\end{abstract}

Key terms: ethical decision-making process, models, Code of ethics, ethics education

JEL Classification: M41

To cite this article: Alina Beattrice Vladu, Dan Dacian Cuzdriorean, Considerations on the Improvement of Ethical Decision Making in the Accounting Profession, CECCAR Business Review, № 1/2022, pp. 44-52, DOI: http://dx.doi.org/10.37945/ cbr.2022.01.06

\section{O Introduction}

On May 10th, 2021, the Ethics board's COVID-19 Working Group and national ethical standard-setters from Australia, Canada, China, South Africa, the UK, and the US (working under the aegis of the International Ethics Standards Board for Accountants (IESBA)) warned about ethical challenges that are set to intensity in the coming months and years. In this respect, both accountants and stakeholders will be under increasing pressure to cut corners. IESBA named five ethical challenges set to intensify as the pandemic moves into a new phase as following: (1) an uneven recovery; (2) demands for greater support and efficiency; (3) rapid digitalization; (4) burn out and mental health issues; (5) focusing on the past and not the future.

Having analyzed the challenges in the accountancy profession during the COVID-19 period, IESBA declared that those are far from over and might intensify as time passes.

One of the most important ethical challenges facing accounting professionals will arise from dealing with clients trying to reset and adjust their businesses in the wake of COVID-19. As this happens, an inherent risk of manipulative behavior arises according to IESBA Working Group and standard-setters, as well as an increased risk for independence (as accounting professionals will face new pressure to support and advice clients both formally and informally). 
Also, rapid digitalization during the pandemic period implies a danger of exposure to cybercrime and not only that. In this regard, there are social and ethical issues arising because of digitalization, based on current dominant technologies used by accounting professionals. As this new wave of digitization during COVID-19 period started, public values were under pressure. The IESBA Working Group and national ethical standard-setters stressed the importance of thoroughly finding and understanding the threats to ethics arising from rapid and extensive digitalization.

All the above underline the importance of improving ethical decision-making. In this respect, the main aim of the paper is to provide an overview regarding the paths contributing to the improvement of the ethical decision-making process: the International Code of Ethics for Professional Accountants (including the International Independence Standards), 2021, IFAC (available at https://www.ethicsboard.org/publications/2021-handbookinternational-code-ethics-professional-accountants) (hereunder Code of ethics); influential ethical decision-making models (hereunder EDM models) from behavioral ethics and accounting field and ethics pedagogy.

The remainder of the paper proceeds as follows: In the next section, we describe the review of literature regarding the findings related to how ethical decision-making can be improved. We also follow with a discussion on the findings in the literature and finally present our conclusion, the study's limitations and avenues for further research.

\section{State of the art}

A key concern in today's business world is truthfulness and integrity. Since ethical violations raised concerns, empirical findings document the magnitude of such phenomenon (Plinio et al., 2010) and propose ways for professional accountants to follow, in order to reduce unethical behavior. Such approach is not an easy one, since ethical challenges are complex and poorly stated, as findings from the literature documented (Thiel et al., 2012). As Cottone et al. (2021) concluded, ethical dilemmas are common and appear in situations as: (1) ethical principles/ standards compete with each other; (2) ethical codes/law/policy are in conflict; (3) conflict between ethical and personal standards; (4) conflict between competing professional roles; (5) conflict between the interests of the parties involved; (6) unethical conduct/practices of other professionals/peers; (7) unclear application of standards due to the complexity of the situation or any other circumstance.

Assessing the magnitude of such phenomenon, Mendes et al. (2016) documented that such challenges occur annually for most practitioners.

When faced with ethical dilemmas, professionals usually make decisions referring to their codes of ethics. As such, the ethical codes of conduct articulate professional values of accountants and are extremely useful in providing guidelines for professional behavior at the workplace. As Johnson et al. (2021) asserted, codes of ethics "often include ideals to strive for within a given practice (i.e., aspirational principles) and concrete enforceable standards".

The Code of ethics used by the accountancy profession plays a significant role and provides important guidelines to be incorporated into graduate training and continuing education and is often needed for licensure and/or membership. However, the guidelines provided by the Code of ethics are not always clearly understood and applied as such. As Johnson et al. (2021) concluded, in certain circumstances, ethical codes of conduct may not be sufficient to explain how professionals make decisions.

Despite the importance and usefulness of such guidelines, sometimes they prove to be insufficient for ethical decision making, especially when different ethical values compete (Johnson et al., 2021). The Code of ethics often suggests the use of EDM models and serves as foundation for them (Johnson et al., 2021). 
Developed mainly in the field of psychology, EDM models can also be useful in guiding accounting professionals in determining the right way when dealing with ethical dilemmas. Today, a large majority of EDM models are available to be used by professionals in all fields. The advantage of using EDM models to either teach ethics to students or as guidance by professional accountants consists in the fact that such demarche can increase individuals' awareness about the factors (e.g., organizational factors) that influence ethical decision making.

Understanding the ethical decision-making process by professional accountants can result in selecting a better course of action when facing ethical dilemmas/challenges. Studies conducted so far in the literature are focusing on understanding the cognitive process used by accountants when deciding right from wrong.

Most of the research in ethical decision making is founded on the cognitive developmental approach to ethics (Kohlberg, 1969; Rest, 1986). Based on their work, the large majority of EDM models were developed trying to either describe the underlying mechanisms of the cognitive process, resulting in ethical decision or predicting the actual behavior of individuals in an ethical situation.

The theoretical framework of Kohlberg (1969) consists of six stages arranged sequentially in successive levels of complexity, as it tries to understand how an individual's moral reasoning is developed as follows:

$\checkmark$ Level 1: preconventional level, wherein it is considered that the individual's morality is externally controlled, behavior being decided by consequences. In stage 1 it is considered that individuals will obey to avoid punishment. Stage 2 discusses the instrumental purpose orientation, where it is considered that individuals focus on receiving rewards or satisfying personal needs.

$\checkmark$ Level 2: conventional level, wherein conformity to social rules remains important for the individual and strives to support rules that are imposed by family members or peers (stage 3 ) and the government (stage 4).

$\checkmark$ Level 3: postconventional level, wherein individuals move beyond the perspective of their society. In this level, morality is defined in terms of universal principles and values that can be applied in all societies (and situations). Moral values are defined based on a social contract including the individual's rights and personal moral values (stage 5) and the universal ethical principle (stage 6 - the highest stage of functioning). The type of reasoning applied in the latter stage involves taking the perspective of every person or group that could potentially be affected by one's decision.

Rest (1969) tries to overcome criticism associated with Kohlberg's work and build upon it an organizing framework including the consideration of crucial factors such as: affect, behavior, self-concept, social information influencing the individual's morality. As a result, a 4-component EDM model was developed, wherein the moral agent must: (1) recognize the moral issue (awareness); (2) make a moral assessment (judgment); (3) prioritize moral concerns in respect to other types of concerns (intention); and (4) act on the moral concerns (behavior).

Other EDM models were developed either by improving the work conducted by Kohlberg and Rest, or by trying to take a new research path as summarized below.

For instance, the work of Treviño (1986) included dispositional factors coupled with situational ones when predicting the ethical decision making of individuals at the workplace. Treviño (1986) considered that such individual difference variables will interact with either the situation or cognitive moral development in determining ethical behavior and proposed what is called in the literature the person-situation interactionist approach to ethical decision making (MacDougall et al., 2014).

On the other hand, Jones (1991) considered that the characteristics which define an ethical issue are reflected in the moral intensity associated with the issue at hand. Based on the author's assertions, moral intensity can influence individuals as follows: issues with higher levels of moral intensity are more important than 
those of low moral intensity. The theoretical framework developed by Jones (1991) included six components believed to affect the moral intensity of a certain situation as follows: (1) value of consequences (total amount of benefit/harm received as a result of a moral act); (2) social consensus (the act is viewed as socially good or bad); (3) probability of the effect (considering the possibility that the act will actually occur, the consequences will be either beneficial or negative); (4) temporal immediacy (the time span until the consequences of the moral act might occur); (5) proximity of the moral issue (social, cultural, psychological implications of the influence of the moral act on the relevant stakeholders); and (6) concentration of effect (relation entrenched between the number of individuals involved and the magnitude of the moral act).

Reynolds (2006) took a different path of research compared to earlier EDM models found in the literature and accounted for intuition. As such, the model proposed was based on matching of prototypes when individuals face an ethical dilemma. In this regard, individuals will compare the new stimuli to pre-existing ones (experiencebased knowledge). Further, this will allow for automatic recognition of a presence of an ethical challenge situation. Based on the author's findings, this process is happening in an automatic and intuitive way, wherein individuals do not make conscious effort during prototype comparison, thus minimizing cognitive load and ease decision making. On the other hand, when confronted with cases of lacking proper prototypes, individuals will take the path of active and deliberate analyzing of information to judge and provide an adequate ground for their intuitions. The usefulness of this model consists in the fact that it accounts for intuition and can explain how individuals make decisions under time pressure (an aspect of paramount importance, given the fact that the professionals in the accounting field are often in this situation).

Sonenshein (2007) and Mumford et al. (2008) focused on developing sensemaking-intuition models having as a result a constructed mental model that can be applied to solving an ethical dilemma when it occurs. Various situational constraints influencing an individual's assessment on a particular issue were considered. The authors acknowledged that situational appraisal results from mixed influences of standards/rules, perceptions and goals. Further, when the situational appraisal is considered as having ethical implications, individuals are framing the situational one, also taking emotions into consideration, while receiving input from a self-reflection (searching memory for prior personal/professional cases to aid decision-making). Forecasting will predict potential outcomes associated with different potential courses of action, while choices are assessed accordingly. Finally, with aid from self-reflection, a final mental model is chosen, deciding further sensemaking activities guiding the decisions applied to the ethical issue at hand.

The latest EDM models found in the literature are looking to integrate character, founded in virtue ethics, into Rest's (1986) EDM model (Nguyen and Crossan, 2021; Sosik et al., 2019; Bright et al., 2014).

The alignment of character with the EDM process proposed by Nguyen and Crossan (2021) allows for introspection into the contextual nature of the model, given the fact that the "ability to exercise a virtue depends on both the character disposition of the moral agent and the context in with the agent operates" (Nguyen and Crossan, 2021).

For many years, the academia strived to understand the cognitive moral development and ethical decisionmaking processes of accounting professionals and, despite the fact that today we can choose from a large number of EDM models to guide us when facing an ethical dilemma, an individual's ability to deal with moral issues is not formed right away, but develops over time and is influenced significantly by educational efforts (according to what Kohlberg (1984) asserted many years ago).

Acknowledging that the professional Code of ethics and EDM models are extremely useful in guiding accounting professionals facing an ethical dilemma, we consider that ethics education/instruction is needed more 
than ever. To change the mindset and eventually the behavior, setting up policies is not enough. As Jackling et al. (2007) asserted, the enhancement of the ethics education is a viable solution for addressing the ethical crisis in the accounting profession. However, if we want the accountancy profession to fully benefit from the ethics education, we must focus on continuously developing proper ethics pedagogies and improving ethics education.

In terms of ethics instruction, despite all the ample research on the topic, there is no consensus on how ethics should be taught (Poje and Zaman, 2021).

According to Bampton and Cowton (2013), the accounting ethics education includes two areas of research. The first is focusing on assessing whether accounting students have a higher or lower moral standard in comparison with other students from other areas. The second stream of research is looking to find out whether the teaching of ethics should be an integrated part of accountancy courses and, if so, whether it has any long-term effect on the moral reasoning of individuals.

Meta-analysis studies, like the one conducted by Christensen et al.'s (2016), documented that when using a pervasive approach (ethics is infused in one or more accounting courses), this can have a positive effect on the moral reasoning of students. Earlier, Dellaportas (2006) documented that a discrete approach (a separate course of ethics from accounting courses) can conduct to an increased ethical reasoning of students. Regardless of the contradictory empirical results documented so far, ethics should be an important part of any curriculum, as testing ethical theories and pedagogies has developed so far.

Various researchers document the use of innovative ethics pedagogies, like Giving Voice to Values (Christensen et al., 2018), active learning (Loeb, 2015), thematic approach (Blanthorne et al., 2007), virtue ethics (Sorensen et al., 2017) or role-playing (Bouten and Hoozée, 2015). Innovative ethics pedagogy was found to be more effective compared to the traditional one.

The empirical study conducted by Christensen et al. (2018) evaluated the effectiveness of two accounting ethics pedagogies (traditional versus action-oriented, known as the Giving Voice to Values pedagogy). The results indicated consistent unethical behavior within the cohort that took part in the traditional pedagogy, but not in the cohort that took part in the action-oriented pedagogy.

While the traditional ethics pedagogy refers to exposing individuals to philosophical theories of ethical decision-making and ethical decision-making frameworks, standards of professional conduct, preparing cases involving unethical behavior engagement and discussions about whistle-blowers speaking about fraud, the action-oriented pedagogy focuses on skill-building to develop confidence in the face of ethical challenges (Christensen et al., 2018). The action-oriented ethics instruction consists in exercises, short study cases, learning new teaching strategies, annotated bibliographies and includes the identification of values (both one's own and those commonly held by other individuals), and the identification of the best communication style and approach working for every individual. As Christensen et al. (2018) asserted, action-oriented learning exercises can provide guidance in strategizing approaches to act in a values challenge, based on one's own strengths. This ethics pedagogy is being helpful in developing the individual voice efficacy and confidence (Cote et al., 2011; Gentile, 2010) by using active learning strategies, found to be more effective compared to passive learning ones (Loeb, 2015).

\section{Discussion}

When facing ethical dilemmas, a variety of paths can be used by professional accountants to assess the riskiness of the outcome. As ethical challenges arise (as IESBA drew attention) accounting practitioners will struggle to assess which is the most proper way to react. 
Starting with the setting up policies path, one course of action consists in following the provisions of the revised Code of ethics (2021), the recommendations developed by the professional organizations or consultation with colleagues and ethics boards. Given the fact that ethical behavior plays a key role in ensuring trust in business practices, financial reporting and good reputation is important for the members of accountancy profession to follow the ethical guidance provided by the fundamental principles of the Code of ethics, as integrity, objectivity, professional competence and due care, confidentiality and professional behavior.

Being a dynamic document, the Code of ethics was restructured not long ago for the purpose of offering professionals in the field the possibility to distinguish requirements very clearly. Besides the increasing clarity compared to the earlier versions, the restructured version provides more guidance towards the issue of addressing and reporting suspected noncompliance with laws and regulations. This step is an important one for accounting professionals serving the public interest.

Given the consequences of unethical practices, professional organizations and scholars alike made efforts to improve the ethical decision-making process. A second path consists in using the EDM models as guidance for improving the ethical decision-making process.

The EDM models assessed above are some of the most influential selected from the large majority documented in the behavioral ethics and accounting field. What those EDM models have in common is the necessity of understanding the ethical decision-making process and further proposing a framework to be used when ethical dilemmas arise.

Even though a large majority of the EDM models were developed since Kohlberg (1969) and Rest (1986), both remained two of the main streams of the research in moral development in the business ethics (as DeTienne et al., 2021, concluded). Wherein the EDM models have developed so far, both personal characteristics and situational factors affecting ethical decision-making process were assessed. Summarizing the earlier findings derived from what we know so far, as regards the factors affecting the ethical decision-making process, both individual (Nahar, 2018) and situational factors (Driskill and Rankin, 2020) are important, the latter gaining more importance over the time. Personal characteristics (e.g., age, gender, education), internalized expectations or organizational expectations are some of the factors affecting moral judgment (Jones and Hiltebeitel, 1995). Situational factors, such as social pressure, treatment effect, culture, profession, professional commitment, importance of outcome, were found to affect the ethical decision-making process.

By analyzing the EDM models, the cognitive process of ethical decision-making becomes more clearly framed, once we understand the way this process is structured and the factors affecting it.

On the other hand, the EDM models are not without limitations. Those need to be considered when the EDM models are used. For instance, the cognitive developmental approach ignores the context of the environment and characteristics of ethical scenarios and do not address the equivocality and uncertainty characteristic of real-life ethical dilemmas. Even though Treviño (1986) introduced the interactive effects of individual and situational factors in an EDM model, other potential key factors were omitted. The Jones (1991) EDM model failed to address the possibility that biases differ across individuals, considering them constant over moral issues. As concluded by MacDougall et al. (2014), this may alter the extent to which individuals assessing an ethical challenge view the issue as a moral one.

Despite the limitations, using ethical decision-making models is considered the best practice for professionals faced with ethical challenges (Handelsman et al., 2009). Having different theoretical or philosophical foundations (rational models, moral reasoning model, virtue model, social constructivist model, collaborative model, integrative model, as classified by Garcia et al., 2004), such models were found to improve the quality of ethical decisionmaking (Luke et al., 2013). 
A third path to improving the considered ethical decision-making process is education. Ethics education in the accounting academic environment includes an extensive body of knowledge and provides particularly useful background information on a variety of educational methods and pedagogies. Focusing on techniques that support the ethics instruction, various paths are described, such as case discussions, frameworks, role-playing, lectures, identification of moral heroes, extensive readings, etc. All those are meant to help individuals in assessing and resolving ethical dilemmas, while outlining several steps to follow in this regard, by using the latest methods in the ethics instruction.

Even though researchers seem to acknowledge the fact that the innovative ethics pedagogy is more effective compared to the traditional one, no consensus exists so far on whether ethics should be taught as a separate course or included into the curriculum (Poje and Zaman, 2021).

Nevertheless, as Poje and Zaman (2021) stated, the moral development of professional accountants is an ongoing process and that is why ethics trainings should continue after formal education.

\section{Conclusion, limits and suggestions for future research}

Previously, the bankruptcy of well-known companies for fraud and unethical behavior emphasized how a disregard for ethics can result in profound negative consequences affecting the status and credibility of the accountancy profession. Also, unexpected events such as the COVID-19 pandemic can open the way to ethical challenges for the accountancy profession.

According to earlier studies conducted so far in the literature (DeTienne et al., 2021), ethical decision making is essential to the business environment. In this respect, improving the ethical decision-making became of paramount importance over the years, as ethics has taken center stage in the accountancy profession. Even though ethical decision-making is an overly complex process by reviewing both theoretical and especially empirical evidence in the field of accounting and psychology, professional accountants can increase their understanding of the process.

Not long ago, the International Code of Ethics for Professional Accountants was revised. Although it is a good path for improvement, this is not enough when guiding professional accountants. Moreover, a constant effort for combining standards-setters' provisions with EDM models and innovative ethics pedagogies will result in improving ethical decision-making quality in the long run.

The main limit of this study consists in the fact that it provides a static view of the current situation.

Even though nonetheless we can still expect novel research focusing on new factors previously disregarded of insufficiently assessed in the literature, further studies will still be focusing on factors affecting the ethical decision-making process. The avenues of future research can assess the effect of different religions, time constraint, multicultural issues or memory overload on the ethical decision-making process. Lastly, future research should focus on ethical decision-making involving the consideration of the team-level phenomenon and the rapid digitalization, as both are important for the accountancy profession.

Future avenues of research in ethics pedagogies can focus not only on what to teach, but also on how to teach. Due to the outbreak of COVID-19, it is up to future research to determine the effect of the online ethics pedagogies and to further assess its impact on the ethical decision-making process in the long run. Also, other area of improvement can focus on comparing the effectiveness of innovative methods used in modern ethics pedagogies. As final remarks, we agree with Mele's assertions (2005) that the aims of the ethics education are to increase moral sensitivity, help individuals to make moral judgments, improve moral behavior and stimulate moral virtues. 


\section{References}

1. Bampton, R., Cowton, C.J. (2013), Taking Stock of Accounting Ethics Scholarship: A Review of the Journal Literature, Journal of Business Ethics, Vol. 114, No. 3, pp. 549-563.

2. Blanthorne, C., Kovar, S.E., Fisher, D.G. (2007), Accounting Educators' Opinions about Ethics in the Curriculum: An Extensive View, Issues in Accounting Education, Vol. 22, No. 3, pp. 355-390.

3. Bouten, L., Hoozée, S. (2015), Challenges in Sustainability and Integrated Reporting, Issues in Accounting Education Teaching Notes, Vol. 30, No. 4, pp. 83-93.

4. Bright, D.S., Winn, B.A., Kanov, J. (2014), Reconsidering Virtue: Differences of Perspective in Virtue Ethics and the Positive Social Sciences, Journal of Business Ethics, Vol. 119, No. 4, pp. 445-460.

5. Christensen, A.L., Cote, J., Latham, C.K. (2016), Insights Regarding the Applicability of the Defining Issues Test to Advance Ethics Research with Accounting Students: A Meta-Analytic Review, Journal of Business Ethics, Vol. 133, No. 1, pp. 141-163.

6. Christensen, A., Cote, J., Latham, C.K. (2018), Developing Ethical Confidence: The Impact of Action-Oriented Ethics Instruction in an Accounting Curriculum, Journal of Business Ethics, Vol. 153, No. 4, pp. 1157-1175.

7. Cote, J., Goodstein, J., Latham, C.K. (2011), Giving Voice to Values: A Framework to Bridge Teaching and Research Efforts, Journal of Business Ethics Education, Vol. 8, No. 1, pp. 370-375.

8. Cottone, R.R., Tarvydas, V.M., Hartley, M.T. (2021), Counselling Ethics and Decision Making, 5th Edition, Springer Publishing Company.

9. Dellaportas, S. (2006), Making a Difference with a Discrete Course on Accounting Ethics, Journal of Business Ethics, Vol. 65, No. 4, pp. 391-404.

10. DeTienne, K.B., Ellertson, C.F., Ingerson, M.C., Dudley, W.R. (2021), Moral Development in Business Ethics: An Examination and Critique, Journal of Business Ethics, No. 3.

11. Driskill, T., Rankin, R. (2020), Cross-Cultural Comparison of Ethical Reasoning of Students in China and the United States, Accounting Education, No. 29, pp. 1-14.

12. Garcia, J., Winston, S., Borzuchowska, B., McGuire-Kuletz, M. (2004), Evaluating the Integrative Model of Ethical Decision Making, Rehabilitation Education, Vol. 18, No. 3, pp. 147-164.

13. Gentile, M.C. (2010), Giving Voice to Values: How to Speak Your Mind when You Know What's Right, Yale University Press.

14. Handelsman, M.M., Knapp, S., Gottlieb, M.C. (2009), Positive Ethics: Themes and Variations, in C.R. Snyder, S.J. Lopez (Editors), Oxford Handbook of Positive Psychology, 2nd Edition, Oxford University Press, pp. 105-113.

15. Jackling, B., Cooper, B.J., Leung, P., Dellaportas, S. (2007), Professional Accounting Bodies' Perceptions of Ethical Issues, Causes of Ethical Failure and Ethics Education, Managerial Auditing Journal, Vol. 22, No. 9 , pp. 928-944.

16. Johnson, M.K., Weeks, S.N., Peacock, G.G., Domenech Rodríguez, M.M. (2021), Ethical Decision-Making Models: A Taxonomy of Models and Review of Issues, Ethics and Behavior, https://doi.org/10.1080/10508 422.2021.1913593.

17. Jones, T.M. (1991), Ethical Decision Making by Individuals in Organizations: An Issue-Contingent Model, The Academy of Management Review, Vol. 16, No. 2, pp. 366-395.

18. Jones, S.K., Hiltebeitel, K.M. (1995), Organizational Influence in a Model of the Moral Decision Process of Accountants, Journal of Business Ethics, Vol. 14, No. 6, pp. 417-431. 
19. Kohlberg, L. (1969), Stages in the Development of Moral Thought and Action, Holt, Rinehart and Winston, New York.

20. Kohlberg, L. (1984), Essays on Moral Development, Vol. 2 - The Psychology of Moral Development: The Nature and Validity of Moral Stages, Harper \& Row, San Francisco.

21. Loeb, S.E. (2015), Active Learning: An Advantageous Yet Challenging Approach to Accounting Ethics Instruction, Journal of Business Ethics, Vol. 127, No. 1, pp. 221-230.

22. Luke, M., Goodrich, K., Gilbride, D. (2013), Intercultural Model of Ethical Decision Making: Addressing Worldview Dilemmas in School Counseling, Counseling and Values, Vol. 58, No. 2, pp. 177-194.

23. MacDougall, A.E., Martin, A.A., Bagdasarov, Z., Mumford, M.D. (2014), A Review of Theory Progression in Ethical Decision-Making Literature, Journal of Organizational Psychology, Vol. 14, No. 2, pp. 9-19.

24. Mendes, S.A., Nascimento, I.M., Abreu-Lima, I.M., Almeida, L.S. (2016), A Study of the Ethical Dilemmas Experienced by School Psychologists in Portugal, Ethics and Behavior, Vol. 26, No. 5, pp. 395-414.

25. Mumford, M.D., Connelly, S., Brown, R.P., Murphy, S.T., Hill, J.H., Antes, A.L., Waples, E.P., Devenport, L.D. (2008), Sense Making Approach to Ethics Training for Scientists: Preliminary Evidence of Training Effectiveness, Ethics and Behavior, Vol. 18, No. 4, pp. 315-339.

26. Nahar, H.S. (2018), Exploring Future Accountants' Academic Fraud (In)Tolerance: Oman Evidence, Journal of Accounting in Emerging Economies, Vol. 8, No. 1, pp. 66-83.

27. Nguyen, B., Crossan, M. (2021), Character-Infused Ethical Decision Making, Journal of Business Ethics, https://doi.org/10.1007/s10551-021-04790-8.

28. Plinio, A.J., Young, J.M., Lavery, L.M. (2010), The State of Ethics in Our Society: A Clear Call for Action, International Journal of Disclosure and Governance, Vol. 7, pp. 172-197.

29. Poje, T., Zaman Groff, M. (2021), Mapping Ethics Education in Accounting Research: A Bibliometric Analysis, Journal of Business Ethics, https://doi.org/10.1007/s10551-021-04846-9.

30. Rest, J.R. (1986), Moral Development: Advances in Research and Theory, University of Minnesota Press, Minneapolis.

31. Reynolds, S.J. (2006), A Neurocognitive Model of the Ethical Decision-Making Process: Implications for Study and Practice, Journal of Applied Psychology, Vol. 91, No. 4, pp. 737-748.

32. Sonenshein, S. (2007), The Role of Construction, Intuition, and Justification in Responding to Ethical Issues at Work: The Sensemaking-Intuition Model, Academy of Management Review, Vol. 32, No. 4, pp. 1022-1040.

33. Sorensen, D.P., Miller, S.E., Cabe, K.L. (2017), Developing and Measuring the Impact of an Accounting Ethics Course that Is Based on the Moral Philosophy of Adam Smith, Journal of Business Ethics, Vol. 140, No. 1, pp. 175-191.

34. Sosik, J.J., Chun, J.U., Ete, Z., Arenas, F.J., Scherer, J.A. (2019), Self-Control Puts Character Into Action: Examining How Leader Character Strengths and Ethical Leadership Relate to Leader Outcomes, Journal of Business Ethics, Vol. 160, No. 3, pp. 765-781.

35. Thiel, C.E., Bagdasarov, Z., Harkrider, L., Johnson, J.F., Mumford, M.D. (2012), Leader Ethical Decision Making in Organizations: Strategies for Sensemaking, Journal of Business Ethics, Vol. 107, No. 1, pp. 49-64, https://doi.org/10.1007/s10551-012-1299-1.

36. Treviño, L.K. (1986), Ethical Decision Making in Organizations: A Person-Situation Interactionist Model, The Academy of Management Review, Vol. 11, No. 3, pp. 601-617.

37. International Ethics Standards Board for Accountants (IESBA), 5 Ethics Challenges that Will Intensify as the Pandemic Wanes, https://www.ethicsboard.org/news-events/2021-05/5-ethics-challenges-will-intensifypandemic-wanes. 